\title{
sciendo Barriers of implementation of pro-environmental activities in supply chains
}

doi:10.2478/mape-2019-0049

Date of submission to the Editor: 04/2018

Date of acceptance by the Editor: 07/2018

MAPE 2019, volume 2, issue 1, pp. 487-495

\section{Anna Maryniak}

ORCID ID: 0000-0002-0828-308X

Poznań University of Economics and Business, Poland

\section{INTRODUCTION}

Nowadays, a necessity to undertake pro-environmental practices at the level of individual links and supply chains is a frequently discussed topic. Still, there is no uniform classification of such undertakings.

For instance, Dubey, Gunasekaran and Papadopoulos (R. Dubey, et al., 2017), as a result of the review of subject literature, have assumed that the following groups can be distinguished among pro-environmental activities: green purchases aiming at manufacturing ecological products, outbound and inbound logistics, production logistics and reverse logistics. Goshen and Kumar (S. Goshen \& E.R. Kumar, 2015) have divided pro-environmental activities in the sequence of flow phases in the supply chain. Wong and co-authors (C.Y. Wong, et al., 2015) have highlighted internal activities (concerning strategic activities) and the ones which concern relations with contractors in outbound and inbound supply chains. Islam and co-authors (S. Isam, et al., 2017) have selected fifteen GSCM activities.

Each of these activities may contribute to improving the image of the enterprise, the well-being of the environment or to increasing economic results directly, e.g. through the implementation of effective technologies, or indirectly through a positive reception of the enterprise among its current and potential customers. It is proved in many scientific papers.

Above all, it is proved that pro-environmental practices have a positive influence on the environmental, economic, market and operating results.

For instance, Roehrich, Hoejmose and Overland (J. Roehrich, et al., 2017) think that by improving GSCM effectiveness, the market share increases, positive financial effects are achieved and the competitive position in the process of selection of contractors out of potential participants in the supply chain also increases. Fang and Zhang (Ch. Fang \& J. Zhang, 2018) have concluded, on the basis of extensive subject literature review, that internal and external GSCM practices are positively connected with the results achieved in favor of internal and external stakeholders. In particular, their relation is the biggest in the operating and economic dimensions. Mumtaz and co-authors (U. Mumtaz, et al., 2018) indicate that, together with the implementation of GSCM practices, there is a decrease in environmental pollution and operating costs. Still, it does not influence an increase of organizational flexibility. Chu and co-

\footnotetext{
*anna.maryniak@gmail.com
} 
authors (S. Chu, et al., 2017) underline operating and environmental benefits. Vanalle and co-authors (R.M. Vanalle, et al., 2017) have concluded that the adoption of GSCM practices is positively connected with economic and environmental results.

Therefore, it is relevant to ask why companies, despite potential advantages which result from the GSCM implementation, do not conduct the discussed activities or undertake them to a limited extent.

\section{GSCM BARRIERS - PRESENT STATE OF RESEARCH}

Most of the publications regarding GSCM come from China, the US, Great Britain, India, Taiwan, Iran, Canada, Brazil (M.L. Tseng, et al., 2019). The authors who most often touch upon this issue include: Sarkis, J., Zhu., G,, Govindan, K., De Sousa Jabbour, A.B.L., Jabbour, C.J.C., Lai, K.H., Geng, Y., Diabat, A.

There are not many empirical studies which involve the Central and Eastern Europe. It also concerns the barriers of implementation of pro-environmental activities in supply chains.

In subject literature, the barriers of implementation of pro-environmental activities are presented, above all, with regard to particular industries. For instance, the studies are conducted in rubber industry (S. Mongkolchaichana and B. Phruksaphanrat, 2019), construction industry (A. Wyawahare \& N. Udawatta, 2017), automotive industry (R. Afroz, et al., 2019), textile industry (A. Majumdar \& S.K. Sinha, 2019), clothing industry (A. Majumdar \& S.K. Sinha, 2018), and cashew industry (M. Agyemang, et al., 2018), footwear industry (M.R. Sarker, et al, 2018) leather industry (M.A. Moktadir, et al., 2018).

In this paper, the focus was concentrated on general result concerning supply chains placed in various industries.

For instance, Veleva and Cue (V.R. Veleva \& B.W. Cue, 2019) prove that while large companies in developed markets have, for the most part, implemented green chemistry strategies, this is not the case for smaller companies and manufacturers in developing countries, such as China and India. Piyathanavong et al. (V. Piyathanavong, et al., 2019) think that various operational environmental sustainability approaches, including green manufacturing (GM), cleaner production $(C P)$, green lean $(G L)$, green supply chain management (GSCM), reverse logistics (RLs) and circular economy (CE) is well-documented in developed nations and a few other countries. Very little has been done to understand this phenomenon in rapidly developing countries, such as Thailand. The study of Piyathanavong et al. (V. Piyathanavong, et al., 2019a) revealed that a large amount of investment capacity, proper training and knowledge are needed to fully implement the studied operational approaches. Kaur et al. (J. Kaur, et al., 2019) have concluded that the results of their study point to the "difficulty in transforming positive environmental attitudes into action" and "lack of awareness about reverse logistics adoption" as the top priority barriers followed by "high cost of hazardous waste disposal", "perception of 'out of responsibility' zone", "lack of $R$ \& D capability on ESER (Environmental and Sustainability Education Research)", and "lack of corporate social responsibility". Arvind Jayant, Mohd Azhar (J. Arvind \& A. Mohd, 2014) have identified a lack of sustainability certification (ISO 14001) and cost of disposal of hazardous products as top level barriers.

They have noted that the following barriers which have influence on GSCM 
implementation are of significant importance: commitment of top management; changes in existing policies and technologies; improve the awareness of environmental issues; training and education; and implementation of efficient materials and waste management systems. In their research, Afroz et al. (R. Afroz, et al., 2019) have concluded that the number one barrier in the automotive sector is "market competition and uncertainty". The second problem is "lack of implementing green practices". Like these two barriers, cost implications, unawareness of customers, lack of corporate social responsibility, lack of globalization, lack of technical assistance from government have been identified as top-level barriers and lack of the government's willingness to invest. Majumdar and Sinha (A. Majumdar \& S.K Sinha, 2019) have concluded that the complexity of green process and system design was found to be the most elementary barrier having the maximum driving power. Lack of consumer support and encouragement, lack of guidance and support from regulatory authorities and high implementation and maintenance cost are the other elementary barriers of green supply chain. Lack of green suppliers is the most dependent barrier which is influenced by all other barriers considered in this research. On the basis of the research, Saade, Thoumy and Sakr (R. Saade, et al., 2019) have concluded that the external stakeholders' pressure and the lack of governmental support hinder the GSCM adoption. Moreover, ISO 14001 certified companies have shown a higher rate of adoption of GSCM. Majumdar and Sinha (A. Majumdar \& S.K. Sinha, 2018) have concluded that the complexity of green process and system design as well as the lack of support from regulatory authorities were found to be the barriers having the maximum driving power. Lack of consumer support and high investment and low economic benefits were also found to be important barriers on the way of green practices. Agyemang et al. (M. Agyemang, et al., 2018) have specified that significant barriers on the way of implementation of pro-environmental activities are increased collaboration with multi-tier suppliers (producer organizations and processors) and strategic support from industry bodies, non-governmental organizations and development agencies. Additionally, there are also operational barriers, lack of internal top-level management commitment, lack of integrated management information and traceability systems, and uncertainty of economic benefits.

\section{OPERATIONALIZATION OF RESEARCH}

In these studies, the original classification of barriers which hinder the implementation of pro-environmental activity was adopted. The notions specified below have the following meanings:

- "GSCM barriers" - all difficulties, which are on the way of implementation of solutions which aim at the creation of a green supply chain, whose source is located both in supply chains and beyond them.

- "GSCM activities" - all activities in supply chains which are of material character (e.g. concerning the selection of packagings) as well as immaterial activities (e.g. referring to the creation of rules of suppliers selection) aiming at the protection of natural environment.

What's more, it was adopted that the "management of green supply chains consists of: designing products and managing their flow up and down the supply chain by the participating entities, with particular attention paid to the needs of natural 
environment" (A. Maryniak, 2017). The logistics (transport, warehousing, inventories) is treated as an element of management of supply chains.

The questions concerning barriers referred to the implementation of activities classified on the basis of review of world subject literature. Therefore, the respondents had a possibility to firstly acquaint themselves with basic GSCM activities.

Taking into account the activities, possible barriers of their implementation have been identified in the first place. Secondly, it was diagnosed which barriers are the greatest problem for the studied entities.

Similarly to GSCM activities, the barriers of their implementation were selected on the basis of review of world literature. In this case, there is no uniform classification.

For instance, Nooru Haq \& Mathiyazhagan (A. Nooru Haq, K. Mathiyazhagan, 2013) have divided barriers into three groups which concern: knowledge (low proenvironmental awareness among the employees, suppliers and customers of the organization), technology (lack of knowledge on new materials and processes, lack of awareness with regard to a possibility of adaptation of reverse logistics, lack of specialized knowledge with regard to new technologies, difficulties in the design of products intended for reuse or recycling), costs (high costs of investment or too low rate of return from investments, high costs of transfer to the new system, costs of storing inventories). In total, the authors have distinguished ten items. Wang and coauthors (Z. Wang, et al., 2016) have distinguished five basic groups of barriers. These include the following types of barriers: external (problem in maintaining proenvironmental suppliers, etc.), technological (too complex product design from the point of view of recycling, etc.), connected with knowledge (lack of knowledge concerning reverse logistics, etc.), financial (low level of return of the engaged funds, etc.) and connected with engagement and support (lack of monitoring of GSCM progress for each industry, taking into account their specifications). Zhu and Geng (Q. Zhu \& Y. Geng, 2013) have concentrated their research only on internal barriers. The authors have selected thirteen barriers without grouping them into particular subjects. A similar number of barriers was taken into account in the research of Balon, Sharma and Barua (V. Balon, et al., 2016). In their work, the authors have distinguished fourteen factors which hinder GSCM implementation. Tseng et al. (M.L. Tseng, et al., 2019) have specified ten internal barriers and six external barriers.

On the basis of the conducted review of subject literature, the following thematical constructs have been distinguished. These include:

- awareness - (e.g. lack of understanding of the supply chain participants with regard to environmental issues; lack of awareness/necessity to co-create GSCM and "green products" on the part of final customers);

- costs - (e.g. too high costs of monitoring suppliers with regard to compliance with pro-environmental requirements; too high costs of pro-environmental technologies and deferred return of costs from these investments);

- relations - (e.g. lack of partnership relations in supply chains; lack of the initiator of GSCM activities in supply chains);

- system - (e.g. lack of external environmental audits of participants of supply chains; low level of transparency of supply chain);

- knowledge - (e.g. lack of GSCM designers, consultants and GSCM implementation experts among recipients/intermediators; lack of widespread exemplary practices concerning GSCM); 
- logistics - (e.g. lack of sufficient supply for warehousing infrastructure in which proenvironmental solutions were introduced; lack of a wide range of modern logistics technologies which aim at the protection of natural environment);

- initiatives - (e.g. lack of industry initiatives; lack of governmental regulations (central/local) and legislation concerning GSCM).

Production enterprises were selected for the purpose of the research, because they are related to the operators of both the lower and the upper supply chain. As a result, it was possible for us to look at the environmental issues from a wider research perspective. The subjects of the research were big and medium-sized enterprises, classified according the Central Statistical Office.

The questionnaire method was used during empirical tasks. In the questionnaire, there were objective questions which concerned the confirmation of occurrence of a given barrier. All questions were closed. The responses were granted with the use of the five-category Likert scale, where: 1 = definitely yes, $2=$ rather yes, 3 = hard to tell, $4=$ rather not, $5=$ definitely not.

The research was implemented under an individual internal grant (granted by the committee of the Poznań University of Economics).

\section{RESULTS AND DISCUSSION}

During the studies, the respondents were asked the following question:

"whether the elements specified below constitute a barrier for the development of the company's pro-environmental activity in supply chains?"

In the first place, the obtained answers were summed up and grouped into thematical constructs. Thirty five test items in seven constructs have been distinguished. On the basis of the conducted studies, it was specified that the greatest barriers (taking into account the answers "definitely yes" and "rather yes") concerning GSCM implementation are connected with the following fields: costs and knowledge. In total, there were respectively $35.5 \%$ end $41.7 \%$ of such answers (Figure 1 ).

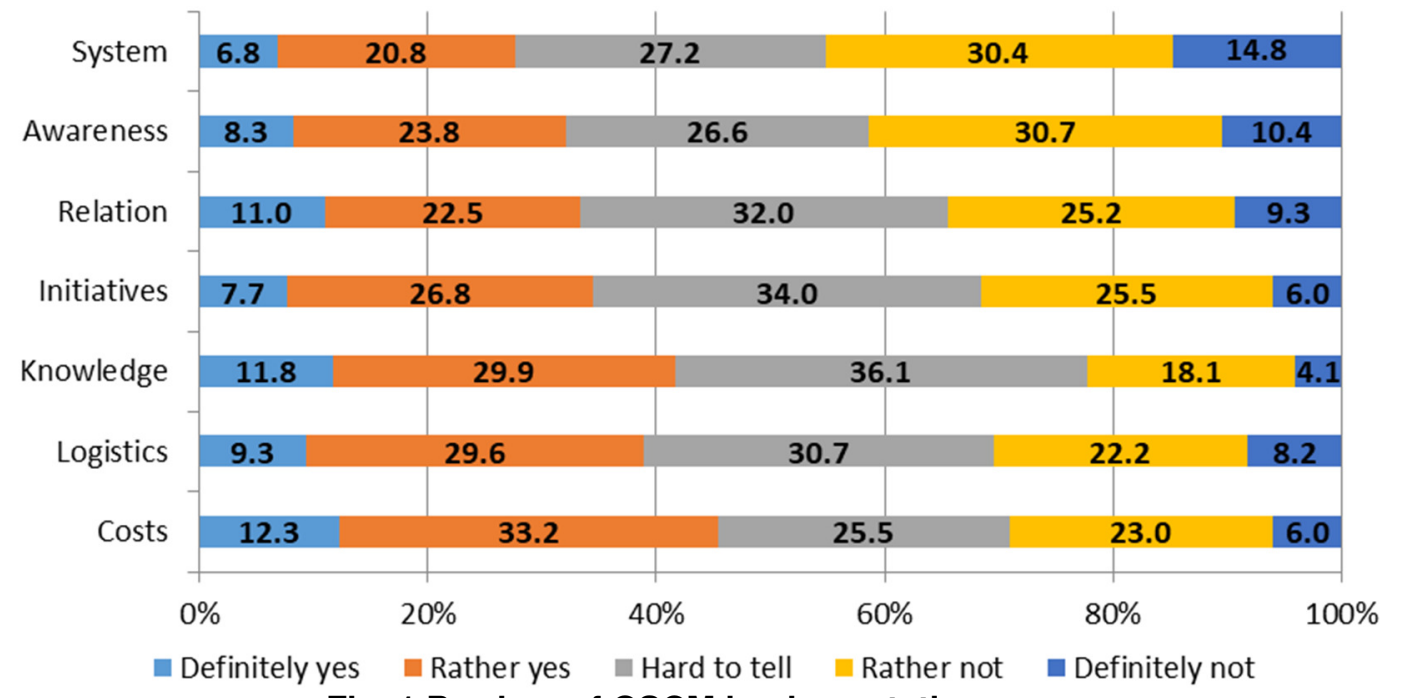

Fig. 1 Barriers of GSCM implementation 
It is connected with the fact that investments into ecological solutions with the partners in supply chains return in the longer run. Additonally, a lack of knowledge in this regard does not stimulate enterprises to undertake such activities. What's more, enterprises are not acquainted with a wide range of possibile pro-environmental solutions. They act "ad hoc", without complex knowledge in this field.

A big percentage of the answer "hard to tell" may indicate that the level of GSCM implementation is so low that it is hard to tell what is an obstacle of their implementation. Repeating studies in the future and presenting them in the dynamic approach would allow us to better diagnose the actual barriers and specify the direction in which they are evolving. Due to the slow, but continuously increasing popularity of GSCM, conducting studies within a short time-frame is not justified.

On the basis of detailed studies, one may conclude that the greatest percentage of responses was connected with costs:

- lack of GSCM designers, consultants and GSCM implementation experts in the company $(75 \%)$,

- to high costs of pro-environmental technologies and deferred return of costs from these investments (73\%),

- too high costs of pro-environmental products, which would cause difficulties in the sales of goods $(68 \%)$,

- lack of the initiator of GSCM activities in supply chains (66\%),

- too high costs of norms and certificates connected with environment protection $(62 \%)$,

- too high costs of monitoring of suppliers with regard to the compliance with proenvironmental requirements (62\%),

- lack of widespread exemplary practices concerning GSCM (60\%).

\section{CONCLUSION}

On the basis of the conducted literature review, it may be concluded that the empirical studies in the Central-Eastern Europe concerning GSCM are not widespread. The conducted research study on Polish entities constitutes a valuable contribution to the knowledge in this regard. It has been established, among other things, that the factors which constitute the barriers of implementation of pro-environmental activities are, above all, connected with cost aspects and with the level of knowledge concerning GSCM. Overcoming these barriers will facilitate adjusting Polish entities to the trends and expectations set by various groups of stakeholders, including, in particular, international supply chains. Increasing competitiveness in this way will provide better possibilities of international development. The implementation of green supply chains in stable structures of vertical links is clear. Still, in the case of agile supply chains and these based on variable networking it may be a big challenge. Therefore, the undertaken considerations should be discussed in more detailed and new contexts should be added to them.

\section{ACKNOWLEDGMENT}

This article was created as part of the implementation of the statutory work of the number: 51112293. 


\section{REFEENCES}

Afroz, R., Rahman, A., Muhibbullah, M. and Morshed, M. (2019). Malaysian automobile industry and green supply chain management. International Journal of Recent Technology and Engineering, 7(6), pp. 158-162.

Afroz, R., Rahman, A., Muhibbullah, M. and Morshed, N. (2019). Malaysian automobile industry and green supply chain management. International Journal of Recent Technology and Engineering, 7(6), pp. 158-162.

Agyemang, M., Zhu, Q., Adzanyo, M., Antarciuc, E. and Zhao, S. (2018). Evaluating barriers to green supply chain redesign and implementation of related practices in the West Africa cashew industry. Resources, Conservation and Recycling, Volume 136, pp. 209222.

Agyemang, M., Zhu, Q., Adzanyo, M., Antarciuc, E. and Zhao, S. (2018). Evaluating barriers to green supply chain redesign and implementation of related practices in the West Africa cashew industry. Resources, Conservation and Recycling, Volume 136, pp. 209222.

Arvind, J. and Mohd, A. (2014). Analysis of the barriers for implementing green supply chain management (GSCM) Practices: An Interpretive Structural Modeling (ISM) Approach. Procedia Engineering 97(2014), pp. 2157-2166.

Balon, V., Sharma, A.K. and Barua, M.K. (2016). Assessment of barriers in green supply chain management using ISM: A case study of the automobile industry in India. Global Business Review, 17(1), pp.116-135.

Chu, S., Yang, H., Lee, M. and Park, S. (2017). The Impact of Institutional Pressures on Green Supply Chain Management and Firm Performance. Top Management Roles and Social Capital, Sustainability, 9(5), pp. 1-21.

Dubey, R., Gunasekaran, A. and Papadopoulos, T. (2017). Green supply chain management: theoretical framework and further research directions. Benchmarking. An International Journal, 24(1), pp. 184-218.

Fang, Ch. and Zhang, J. (2018). Performance of green supply chain management: A systematic review and meta-analysis. Journal of Cleaner Production, Voume183, pp. 1064-1081.

Goshen, S. and Kumar, E.R. (2015). The Implementation of Green Supply Chain Management Practices in Automobile Industry. International Journal of Innovative Research in Science, Engineering and Technolog, 4(4), pp. 233-237.

Kaur, J., Sidhu, R., Awasthi, A. and Srivastava, S.K. (2019). A Pareto investigation on critical barriers in green supply chain management. International Journal of Management Science and Engineering Management, Volume 142, pp. 113-123.

Isam, S., Karia, N., Fauzi, F.B.A. and Soliman, S.S.M. (2017). A review on green supply chain aspects and practices. Management and Marketing, Challenges for the Knowledge Society, 12(1), pp. 12-36.

Majumdar A. and Sinha, S.K. (2019). Analyzing the barriers of green textile supply chain management in Southeast Asia using interpretive structural modeling. Sustainable Production and Consumption, Volume 17, pp. 176-187.

Majumdar, A. and Sinha, S.K. (2018). Modeling the barriers of green supply chain management in small and medium enterprises: A case of Indian clothing industry. Management of Environmental Quality. An International Journal, 29(6), pp. 1110-1122.

Majumdar, A. and Sinha, S.K. (2018). Modeling the barriers of green supply chain management in small and medium enterprises: A case of Indian clothing industry. Management of Environmental Quality: An International Journal, 29(6), pp. 1110-1122.

Majumdar, A. and Sinha, S.K. (2019). Analyzing the barriers of green textile supply chain management in Southeast Asia using interpretive structural modeling. Sustainable Production and Consumption, Volume 17, pp. 176-187.

Maryniak, M. (2017). Zarządzanie zielonym łańcuchem dostaw. Poznań: Wydawnictwo Uniwersytetu Ekonomicznego w Poznaniu.

Moktadir, M.A., Ali, S.M., Rajesh, R. and Paul, S.K. (2018). Modeling the interrelationships among barriers to sustainable supply chain management in leather industry. Journal of Cleaner Production, Volume 181, pp. 631-651.

Mongkolchaichana, S. and Phruksaphanrat, B. (2019). A Comparison of Prioritization Methods for Green Supply Chain Management Criteria Evaluation. 2019 IEEE 6th International Conference on Industrial Engineering and Applications, ICIEA, pp. 313-317. 
Mumtaz, U., Ali, Y. and Petrillo, A. (2018). A linear regression approach to evaluate the green supply chain management impact on industrial organizational performance. Science of the Total Environment, Volume 624, pp. 162-169.

Nooru Haq, A. and Mathiyazhagan, K. (2013). Comparative Study of Green Supply Chain: Barrier Analysis, 4th International Conference on Mechanical. Production and Automobile Engineering (ICMPAE'2013) October 6-7, Dubai (UAE).

Piyathanavong, V., Garza-Reyes, J.A, Kumar, V., Maldonado-Guzmán, G. and Mangla, S.K. (2019a). The adoption of operational environmental sustainability approaches in the Thai manufacturing sector. Journal of Cleaner Production, Volume 220, pp. 507-528.

Piyathanavong, V., Garza-Reyes, J.A., Kumar, V., Maldonado-Guzmán, G. and Mangla S.K. (2019). The adoption of operational environmental sustainability approaches in the Thai manufacturing sector. Journal of Cleaner Production, Volume 220, pp. 507-528.

Roehrich, J., Hoejmose, S. and Overland, V. (2017). Driving green supply chain management performance through supplier selection and value internalisation. International Journal of Operations \& Production Management, 37(4) pp. 489-509.

Saade, R., Thoumy, M. and Sakr, M. (2019). Green supply chain management adoption in Lebanese manufacturing industries: An exploratory study. International Journal of Logistics Systems and Management, 32(3-4), pp. 520-547.

Sarker, M. R., Ahmed, F., Deb, A.K. and Chowdhury, M. (2018). Identifying barriers for implementing Green Supply Chain Management (Gscm) In footwear industry of Bangladesh: A Delphi study approach. Leather and Footwear Journal, 18(3), pp. 175186.

Tseng, L.M., Islam, M.S., Karia, N., Fauzi, F.A. and Afrin, S. (2019). A literature review on green supply chain management: Trends and future challenges. Resources, Conservation and Recycling, Volume 141, pp. 145-162.

Tseng, M.L., Islam, M.S., Karia, N., Fauzi, F.A. and Afrin, S. (2019). A literature review on green supply chain management: Trends and future challenges, Resources. Conservation and Recycling, Volume 141, pp. 145-162.

Vanalle, R.M., Gilberto, M.D.G., Moacir, G.F. and Wagner, C.L. (2017). Green supply chain management: An investigation of pressures, practices, and performance within the Brazilian automotive supply chain. Journal of Cleaner Production, 10(151), pp. 250-259.

Veleva, V.R. and Cue, B.W. (2019). The role of drivers, barriers, and opportunities of green chemistry adoption in the major world markets. Current Opinion in Green and Sustainable Chemistry, Volume 19, pp. 30-36.

Wang, Z., Mathiyazhagan, K., Xu, L. and Diabat, A. (2016). A decision making trial and evaluation laboratory approach to analyze the barriers to Green Supply Chain Management adoption in a food packaging company. Journal of Cleaner Production, Volume 117, pp. 19-28.

Wong, C.Y., Wong, C.W.Y. and Boonitt, S. (2015). Integrating environmental Management into supply chains. International Journal of Physical Distribution \& Logistics Management, 45(1-2), pp. 43-68.

Wyawahare, A. and Udawatta, N. (2017). A Framework for Successful Implementation of Green Supply Chain Management (GSCM) in Construction Organisations. EPiC Series in Education Science, Volume 1, pp. 402-410.

Zhu, Q. and Geng, Y. (2013). Drivers and barriers of extended supply chain practices for energy saving and emission reduction among Chinese manufacturers. Journal of Cleaner Production, Volume 40, pp. 6-12. 
Abstract. A constant growth of interest in GSCM on the part of business practitioners creates a need to develop research within this field. One of the basic questions is why, despite numerous evidence of benefits resulting from the use of proenvironmental practices in supply chains, the level of GSCM implementations is low. Therefore, the aim of the paper is determining which barriers constitute the greatest obstacles on the way of GSCM implementation. The studies were conducted among Polish market entities. Therefore, they were prepared in the part of Europe in which there are not many studies regarding this topic. As a result of the conducted studies, it was determined that the greatest barriers for pro-environmental practices are included in the field which concerns knowledge and cost. What is more, the importance of particular barriers was specified in the paper.

Keywords: barriers implementation of green supply chains, CSR, environmental protection, logistics 